\title{
An Air-Ocean Coupled Nowcast/Forecast System for the East Asian Marginal Seas
}

\author{
Peter C. Chu, Shihua Lu, and Chenwu Fan \\ Naval Postgarduate School, Monterey, California
}

September 12,2000

\section{Introduction}

The South China Sea (SCS), Yellow/East China Sea (YES), and Japan/East Sea (JES) are major east Asian marginal seas (EAMS). The complex topography includes the broad shallows of the Sunda Shelf in the south/southwest of SCS; the continental shelf of the Asian landmass in the north, extending from the Gulf of Tonkin to the YES; a deep, elliptical shaped SCS and JES basins, and numerous reef islands and underwater plateaus scattered throughout (Fig. 1a). The shelf that extends from the Gulf of Tonkin to the YES is consistently near $70 \mathrm{~m}$ deep, and averages $150 \mathrm{~km}$ in width.

The EAMS is subjected to a seasonal monsoon system. From April to August, the weaker southwesterly summer monsoon winds result in a wind stress of just over $0.1 \mathrm{~N} / \mathrm{m}^{2}$. From November to March, the stronger northeasterly winter monsoon winds corresponds to a maximum wind stress of nearly $0.3 \mathrm{~N} / \mathrm{m}^{2}$. Recent observational studies show that the EAMS is energetic and has multi-eddy structure. For example, the SCS synoptic eddy structure was identified in May 1995 using the airborne expendable bathythermograph (AXBT) data (Chu et al., 1998a), the eddy spatiotemporal scales in the YES were identified using the Navy's Master Oceanographic Observational Data Set (MOODS) during 19291991 (Chu et al., 1997a,b), and the seasonal JES multi-eddy structure from a composite analysis on the U.S. National Centers for Environmental Prediction (NCEP) monthly SST fields during 1981-1994 (Chu et al. 1998b).

The fundamental scientific issues are: What are the dynamical balances controlling mesoscale eddy variations in the EAMS, including the effect of wind and thermohaline forcing, wave processes, current instabilities, coastline geometry and topographic slope? What is the role of coastal air-ocean coupling on oceanic and atmospheric dynamics of mesoscale eddies? To study these problems, a coastal atmosphere-ocean coupled system (CAOCS) was developed at the Naval Postgraduate School. The model domain $\left(67^{\circ}-142^{\circ} \mathrm{E}, 7^{\circ} \mathrm{S}-55^{\circ} \mathrm{N}\right)$ covers the whole EAMS and surrounding land and islands. The surface fluxes of water, heat (excluding solar radiation), and momentum are applied syn- 
chronously with opposite signs in the atmosphere and ocean. Flux adjustments are not used.

\section{CAOCS for the EAMS Nowcast/Forecast}

\subsection{Ocean Component}

\subsubsection{Numerics}

The CAOCS ocean component (i.e., the POM) is a time dependent, primitive equation circulation model on a three dimensional grid that includes realistic topography and a free surface. From a series of numerical experiments (Chu et al., $1998 \mathrm{a} ; 1999 \mathrm{a}, \mathrm{b} ; 2000 \mathrm{~b}$ ), the qualitative and quantitative effects of non-linearity, wind forcing and lateral boundary transport on the EAMS are analyzed, yielding considerable insight into the external factors affecting the regional oceanography. We use a rectilinear grid with horizontal spacing of $0.25^{\circ}$ by $0.25^{\circ}$ and 23 nonuniform vertical $\sigma$ levels. The model uses realistic bathymetry data from the Naval Oceanographic Office Digital Bathymetry Data Base with 5 minute resolution (DBDB5).

\subsubsection{Open Boundary Conditions}

Closed lateral boundaries, i.e., the modeled ocean bordered by land, were defined using a free slip condition for velocity and a zero gradient condition for temperature and salinity. No advective or diffusive heat, salt or velocity fluxes occur through these boundaries.

At open boundaries, we use monthly varying volume transports from a global inverse model (Chu and Fan, 2000) for the open boundaries (Fig. 1a). When the water flows into the model domain, temperature and salinity at the open boundary are likewise prescribed from the climatological data. When water flows out of the domain, the radiation condition was applied,

$$
\frac{\partial}{\partial t}(\theta, S)+U_{n} \frac{\partial}{\partial n}(\theta, S)=0
$$

where the subscript $n$ is the direction normal to the boundary.

\subsubsection{Initial Conditions and Model Initialization}

Before coupling to the atmospheric model that is MM5, the POM model was integrated for four years and four months from zero velocity, and January climatological temperature and salinity fields and forced by monthly mean surface wind stress from the Comprehensive Ocean and Atmosphere Data Set (COADS) and by the restoring-type surface heat and salinity fluxes which are relaxed to the surface monthly values. The final states of temperature, salinity, and velocity were taken as the initial ocean conditions for 1 April 1998. 


\subsection{Atmospheric Component}

\subsubsection{Model Description}

We take Version-3 of the Fifth-Generation Penn State University/NCAR Mesocale Model (MM5) as the atmospheric component for CAOCS. The MM5 is a limited-area, nonhydrostatic, terrain-following sigma-coordinate model designed to simulate or predict mesoscale and regional-scale atmospheric circulation. It has been developed at Penn State and NCAR as a community mesoscale model and is continuously being improved by contributions from users at several universities and government laboratories.

\subsubsection{Land Surface Parameterization}

The horizontal resolution is $60 \mathrm{~km}$. Sixteen pressure levels were used with the top at $10 \mathrm{mb}$. A soil water availability function was used for computing the soil water content by using 10 specified vegetation types. Dominant deciduous and coniferous forests cover the most land areas. There are small areas of tropical forest in Taiwan, and Indo-China Peninsula.

\subsubsection{Initial and Lateral Boundary Conditions}

The initial and horizontal lateral boundary conditions for wind, temperature, water vapor, and surface pressure are interpolated from analyses of observations from European Center for Medium-Range Weather Forecasts (ECMWF). For the present study, they were projected on a spectral T42 grid, and a vertical resolution of 14 pressure levels. The initial conditions were the fields on $00 \mathrm{Z}$ April 1, 1998. The lateral boundary conditions were provided via a relaxation method and updated every 12 hours.

\subsection{Ocean-Atmosphere Coupling}

Atmospheric and oceanic surface fluxes of water, heat (excluding solar radiation), and momentum are of opposite sign and are applied synchronously. Flux adjustments are not used. We use the same flux parameterization as the MM5 for CAOCS. The only difference between the two is the use of sea surface temperature (SST) data. In stand-alone MM5 model, SST is prescribed as a given parameter. However, in the CAOCS, SST is predicted by the POM model at each time step for the atmospheric component (MM5).

\section{Predicted EAMS Circulation}

We integrate the CAOCS model for four months from 1 April 1998. Figures $1 \mathrm{~b}, \mathrm{c}, \mathrm{d}$ show the predicted temperature and velocity vector fields at three different depths (surface, 50m, and $200 \mathrm{~m}$ ) in June 1998. The North Equatorial 
Current (NEC) was well predicted in all depths. After encountering the western boundary along the Philippine coast, the NEC bifurcates into the northward flowing Kuroshio and the southward flowing Mindanao Current (MC).

The MC and the simulated New Guinea Coastal Undercurrent flow equatorward, feeding both the North Equatorial Counter Current (NECC) and the flow from the Pacific to the Indian Ocean, that is, the Indonesian throughflow. The MC is an essential part of the shallow, wind and buoyancy flux driven subtropical circulation cell that carries the subtropical waters to the equator. It is typically colder and fresher than the South Equatorial Current (SEC) and the New Guinea Coastal Current over the thermocline, due to ventilation in the North Pacific subtropical gyre. The northward flowing Kuroshio is the major western boundary current in the Pacific Ocean. The Kuroshio Water intrudes into the SCS through the southern Luzon Strait (the strait between Taiwn and Phillippines), loops around anticyclonically, bifurcates southwest of Taiwan into the northeast flowing South China Sea Warm Current (SCSWC) and southeast flowing current which exits the SCS through the northern Luzon Strait. In the SCS, a multi-eddy structure was predicted with central SCS warm anticylonic eddy with several surrounding cyclonic eddies. The continuation of the SCSWC becomes the Taiwan Warm Current after passing the Taiwan Strait. Major current system in the EAMS were realistically predicted using the CAOCS. The flow pattern is consistent with recent observational studies (e.g., Chu and $\mathrm{Li}$ 2000) and earlier studies. Interested readers are referred to a recent review paper on the EAMS (Su 1998).

The CAOCS model was assessed using the data collected from the intensive observational period (IOP) of the international South China Sea Monsoon Experiment (SCSMEX) and from the Navy's AXBT measurements in AprilAugust 1998.

\section{CONCLUSIONS}

The CAOCS has capability to predict the current system and thermal structure of the EAMS. Comparing to the SCSMEX and AXBT measurements, the CAOCS successfully predicted the South China Sea multi-eddy structure during the SCSMEX IOP in 1998. These warm-core and cool-core eddies have radii varying from $100 \mathrm{~km}$ to $300 \mathrm{~km}$ and maximum tangential velocities ranging from $10 \mathrm{~cm} / \mathrm{s}$ to $20 \mathrm{~cm} / \mathrm{s}$. The cool-core eddies are cyclonic and the warm-core eddies are anticyclonic.

\section{Acknowledgments}

The authors wish to thank George Mellor and Tal Ezer of the Princeton University for most kindly providing them with a copy of the POM code, and to appreciate the Pennsylvania State University/ National Center for Atmospheric Research (PSU/NCAR) mesoscale modeling group for allowing them to use the 
MM5. This work was funded by the Office of Naval Research NOMP Program, the Naval Oceanographic Office, and the Naval Postgraduate School.

\section{References}

[1] Blumberg, A., and Mellor, G. (1987) A description of a three dimensional coastal ocean circulation model, Three-Dimensional Coastal Ocean Models, edited by N.S. Heaps, American Geophysics Union, Washington D.C., 1-16.

[2] Chu, P.C., Tseng, H.C., Chang, C.P., and Chen, J.M. (1997a) South China Sea warm pool detected in spring from the Navy's Master Oceanographic Observational Data Set (MOODS). J. Geophys. Res., 102, 15761-15771.

[3] Chu, P.C., Lu, S.H., and Chen, Y.C. (1997b) Temporal and spatial variabilities of the South China Sea surface temperature anomaly. J. Geophys. Res., 102, 20937-20955.

[4] Chu, P.C., Chen, Y.C., and Lu, S.H. (1998a) Wind-driven South China Sea deep basin warm-core/cool-core eddies. J. Oceanogr., 54, 347-360.

[5] Chu, P.C., Fan, C.W., Lozano, and Kerling, J.L. (1998b) An airborne expandable bathythermograph survey of the South China Sea, May 1995. J. Geophys. Res., 103, 21637-21652.

[6] Chu, P.C., Edmons, N.L., and Fan, C.W. (1999a) Dynamical mechanisms for the South China Sea seasonal circulation and thermohaline variabilities. J. Phys.Oceanogr., 29, 2971-2989.

[7] Chu, P.C., Lu, S.H., and Liu, W.T. (1999b) Uncertainty of the South China Sea prediction using NSCAT and NCEP winds during tropical storm Ernie 1996. J. Geophys. Res., 104, 11273-11289.

[8] Chu, P.C., and Li, R.F. (2000): South China Sea isopycnal surface circulations. J. Phys. Oceanogr., 30, 2419-2438.

[9] Chu, P.C., Lan, J., and Fan, C.W. (2000a) Japan/East Sea (JES) circulation and thermohaline structure, Part 1 Climatology. J. Phys. Oceanogr., in press.

[10] Chu, P.C., Veneziano, J. M., and Fan, C.W. (2000b) Response of the South China Sea to tropical cyclone Ernie 1996. J. Geophys. Res., 105, 1399114009.

[11] SCSMEX Science Working Group (1995) The South China Sea Monsoon Experiment (SCSMEX) Science Plan. NASA/Goddard Space Flight Center, Greenbelt, 65pp.

[12] $\mathrm{Su}, \mathrm{J}$. (1998) Circulation dynamics of the China seas north of $18^{\circ} \mathrm{N}$. The Sea, 11, 483-505. 

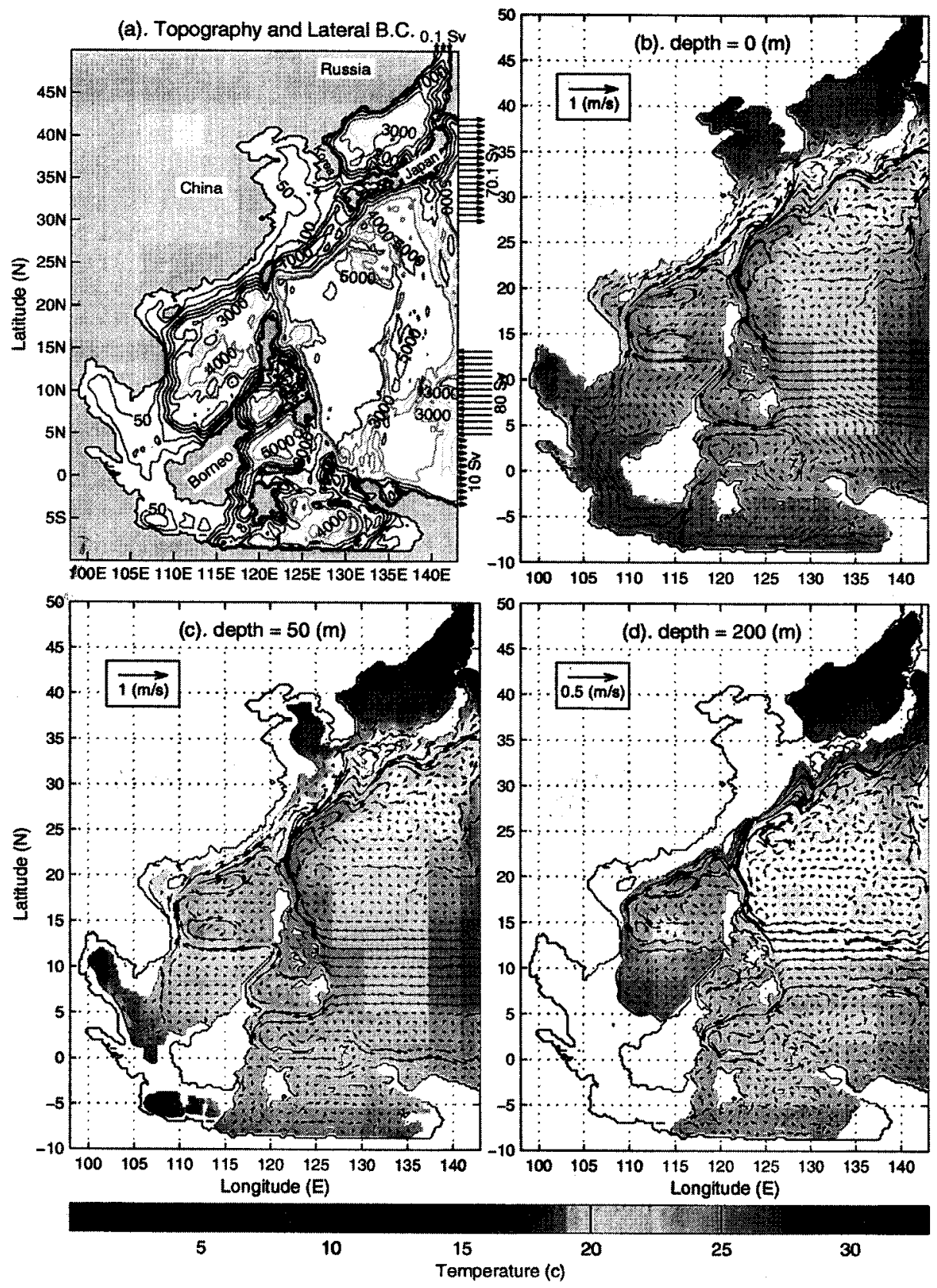

Fig. 1. Predicted temperature and velocity fields in June 1998 